\title{
Advanced hepatocellular carcinoma with hepatic vein tumor thrombosis and renal dysfunction after hepatic arterial infusion chemotherapy effectively treated by liver resection with active veno-venous bypass: report of a case
}

Atene Itoh ${ }^{1}$, Hiroshi Sadamori ${ }^{1 *}$, Kazuhisa Yabushita ${ }^{2}$, Kazuteru Monden ${ }^{1}$, Masashi Tatsukawa ${ }^{2}$, Masayoshi Hioki ${ }^{1}$, Tsuyoshi Hyodo ${ }^{3}$, Kunihiro Omonishi ${ }^{4}$, Toru Ueki ${ }^{2}$, Satoshi Ohno ${ }^{1}$, Kohsaku Sakaguchi ${ }^{2}$ and Norihisa Takakura ${ }^{1}$

\begin{abstract}
Background: Hepatocellular carcinoma (HCC) patients with hepatic vein tumor thrombosis (HVTT) extending to the inferior vena cava (IVC) have an extremely poor prognosis. Here we report a case of HCC with HVIT and renal dysfunction after hepatic arterial infusion chemotherapy (HAIC) successfully treated by liver resection and active veno-venous bypass.
\end{abstract}

Case presentation: A 77-year-old man was diagnosed to have a large HCC with intrahepatic metastases and HVTT extending to the IVC. Due to the advanced stage, HAIC with cisplatin was performed 13 times in a period of 17 months. As a consequence of this treatment, the size of the main HCC markedly decreased, and the advanced part of the HVIT went down to the root of the right hepatic vein (RHV). However, because of renal dysfunction, HAIC with cisplatin was discontinued and right hepatectomy with patch graft venoplasty of the root of the RHV was performed. Because progression of renal dysfunction had to be avoided, veno-venous bypass was activated during IVC clamping to prevent renal venous congestion and hypotension. Histological examination showed foci of a moderately differentiated HCC with extensive fibrosis and necrosis in the main HCC. Histologically, the HVTT in the RHV showed massive necrosis and tightly adhered to the vascular wall of the RHV. The postoperative function of the remnant liver was good, and no further deterioration of renal function was detected. The patient did not show signs of recurrence 15 month after surgery.

Conclusion: In the present case, HAIC using cisplatin in combination with hepatic resection and patch graft venoplasty of the IVC provided a good long-term outcome with no HCC recurrence. Renal function was preserved by using active veno-venous bypass during IVC clamping to prevent renal venous congestion and hypotension.

Keywords: Hepatic arterial infusion chemotherapy, Hepatic vein tumor thrombosis, Hepatocellular carcinoma, Liver resection, Renal dysfunction, Veno-venous bypass

(Continued on next page)

\footnotetext{
*Correspondence: sadamorih@yahoo.co.jp

'Department of Gastroenterological Surgery, Fukuyama City Hospital, 5-23-1

Zao, Fukuyama 721-8511, Japan

Full list of author information is available at the end of the article
} 
(Continued from previous page)

Abbreviations: AFP, Alpha-fetoprotein; ALT, Alanine aminotransferase; AST, Aspartate amino transferase; CT, Computed tomography; eGFR, Estimated glomerular filtration rate; HAIC, Hepatic arterial infusion chemotherapy; HBV, Hepatitis B virus; HCC, Hepatocellular carcinoma; HCV, Hepatitis C virus; HVE, Hepatic vascular exclusion; HVTT, Hepatic vein tumor thrombosis; ICG-R15, Indocyanine green dye retention rate at 15 min; IVC, Inferior vena cava; PIVKA-II, Serum protein induced by vitamin K absence or antagonist; Pt, Platinum; PT-INR, Prothrombin time-international normalized ratio; RHV, Right hepatic vein; SVC, Superior vena cava

\section{Background}

Macrovascular invasion has been recognized as one of the most important prognostic parameters for patients with advanced hepatocellular carcinoma (HCC) [1, 2]. HCC patients with hepatic vein tumor thrombosis (HVTT) extending to the inferior vena cava (IVC) have an extremely poor prognosis [3, 4]. Surgical resection or chemotherapy can provide an acceptable long-term outcome in selected HCC patients with HVTT [5-7].

Here we report the case of a patient with advanced HCC showing HVTT extending to the IVC that was effectively treated by hepatic arterial infusion chemotherapy (HAIC) using powdered cisplatin (CDDP). Due to progressive renal dysfunction, HAIC was discontinued, and the liver was successfully resected with patch graft venoplasty of the root of the right hepatic vein (RHV). To avoid progression of renal dysfunction, active veno-venous bypass was used during IVC clamping, thus preventing renal venous congestion and hemodynamic instability.

\section{Case presentation}

\section{Case report}

A 77-year-old man was admitted to our hospital for the treatment of a liver tumor. His body mass index was $25 \mathrm{~kg} / \mathrm{m}^{2}$, and he had a history of diabetes mellitus and hypertension. Laboratory tests on admission showed the following results: alanine aminotransferase (ALT), $68 \mathrm{IU} / \mathrm{L}$ (normal, 7-37 IU/L); aspartate amino transferase (AST), 104 IU/L (normal, 13-34 IU/L); serum albumin, $4.3 \mathrm{~g} / \mathrm{dL}$; prothrombin time/international normalized ratio (PT/INR), 0.99; total serum bilirubin, $0.8 \mathrm{mg} / \mathrm{dL}$; and indocyanine green dye retention rate at 15 min (ICG-R15), 14.5 \% (Table 1). The Child-Pugh score was 5; serum creatinine and estimated glomerular filtration rate (eGFR) were $1.25 \mathrm{mg} / \mathrm{dL}$ and $43.7 \mathrm{~mL} / \mathrm{min} /$ $1.73 \mathrm{~m}^{2}$, respectively. Serological findings for hepatitis $B$ virus $(\mathrm{HBV})$ and hepatitis $\mathrm{C}$ virus $(\mathrm{HCV})$ were as follows: hepatitis B surface antigen (-), hepatitis B surface antibody $(-)$, hepatitis B core antibody (-), and HCV antibody (-).

Table 1 Laboratory data on admission

\begin{tabular}{|c|c|c|c|c|c|}
\hline \multicolumn{4}{|c|}{ Complete blood count } & \multicolumn{2}{|c|}{ HBV and HCV serology } \\
\hline WBC & $6,700 / \mu \mathrm{L}$ & ChE & $292 \mathrm{IU} / \mathrm{L}$ & $\mathrm{HBsAg}$ & $(-)$ \\
\hline $\mathrm{RBC}$ & $480 \times 10^{4} / \mu \mathrm{L}$ & $\mathrm{LDH}$ & $261 \mathrm{IU} / \mathrm{L}$ & $\mathrm{HBs} A b$ & $(-)$ \\
\hline $\mathrm{Hb}$ & $14.1 \mathrm{~g} / \mathrm{dL}$ & T-Chol & $245 \mathrm{mg} / \mathrm{dL}$ & $\mathrm{HBeAg}$ & $(-)$ \\
\hline $\mathrm{Hct}$ & $43.0 \%$ & $\mathrm{TP}$ & $7.4 \mathrm{~g} / \mathrm{dL}$ & $\mathrm{HBeAb}$ & $(-)$ \\
\hline \multirow[t]{2}{*}{ Plt } & $24.9 \times 10^{4} / \mu \mathrm{L}$ & Alb & $4.3 \mathrm{~g} / \mathrm{dL}$ & $\mathrm{HBCAb}$ & $(-)$ \\
\hline & & $\mathrm{Na}$ & $139 \mathrm{mEq} / \mathrm{L}$ & HCVAb & $(-)$ \\
\hline \multicolumn{2}{|c|}{ Coagulation tests } & K & $4.8 \mathrm{mEq} / \mathrm{L}$ & & \\
\hline PT-INR & 0.99 & $\mathrm{Cl}$ & $101 \mathrm{mEq} / \mathrm{L}$ & Tumor markers & \\
\hline APTT & $32.3 \mathrm{sec}$ & $\mathrm{Ca}$ & $9.4 \mathrm{mg} / \mathrm{dL}$ & AFP & 46,300 ng/mL \\
\hline \multicolumn{2}{|c|}{ Blood chemistry } & UA & $7.9 \mathrm{mg} / \mathrm{dL}$ & PIVKA-II & $28,555 \mathrm{mAU} / \mathrm{mL}$ \\
\hline AST & $104 \mathrm{IU} / \mathrm{L}$ & UN & 17.6 mg/dL & & \\
\hline ALT & $68 \mathrm{IU} / \mathrm{L}$ & $\mathrm{Cr}$ & $1.25 \mathrm{mg} / \mathrm{dL}$ & Dye clearance test & \\
\hline ALP & $353 \mathrm{IU} / \mathrm{L}$ & CRP & $0.28 \mathrm{mg} / \mathrm{dL}$ & ICG-R 15 & $14.5 \%$ \\
\hline$\gamma G T P$ & $175 \mathrm{IU} / \mathrm{L}$ & $\mathrm{HbA1c}$ & $7.5 \%$ & & \\
\hline T.Bil & $0.8 \mathrm{mg} / \mathrm{dL}$ & eGFR & $43.7 \mathrm{~mL} / \mathrm{min} / 1.73 \mathrm{~m}^{2}$ & & \\
\hline
\end{tabular}

AFP alpha-fetoprotein, Alb albumin, ALT alanine aminotransferase, ALP alkaline phosphatase, APTT activated partial thromboplastin time, AST aspartate aminotransferase, ChE cholinesterase, CRP C-reactive protein, eGFR estimated glomerular filtration rate, $\gamma G T P$ gamma glutamyl transpeptidase, $H B V$ hepatitis $B$ virus, $H b$ hemoglobin, $H b A 1 c$ hemoglobin A1c, Hct hematocrit, HCV hepatitis C virus, ICG-R 15 indocyanine green dye retention rate at 15 min, LDH lactate dehydrogenase, PIt platelets, PT-INR prothrombin time-international normalized ratio, $R B C$ red blood cells, T.Bil total bilirubin, T.Chol total cholesterol, PIVKA-Il protein induced by vitamin $\mathrm{K}$ absence or antagonist, $T P$ total protein, UA uric acid, UN urea nitrogen, WBC white blood cells 
Serum alpha-fetoprotein (AFP) was 46,300 ng/mL (nor$\mathrm{mal},<10 \mathrm{ng} / \mathrm{mL}$ ), and serum protein induced by vitamin $\mathrm{K}$ absence or antagonist (PIVKA-II) was $28,555 \mathrm{mAU} / \mathrm{mL}$ (normal, <28 mAU/mL).

Abdominal computed tomography (CT) showed a large HCC with intrahepatic metastasis (Fig. 1a) and HVTT extending from the RHV to the IVC (Fig. 1b). Because of the advanced stage of the HCC, HAIC was started by placing a standard angiography catheter in the right hepatic artery and subcutaneously connecting it to a port system (Piolax Medical Device Co., Ltd, Yokohama, Japan) inferior to the groin. Powdered CDDP, IA-call ${ }^{\circ}$ (Nippon Kayaku Co., Ltd, Tokyo, Japan), was used for HAIC. CDDP was generally administered with a total dose of $65 \mathrm{mg} / \mathrm{m}^{2}$ via the right hepatic artery every 4-6 weeks. To prevent nephrotoxicity, adequate hydration was ensured before and after drug administration by intravenous infusion (1000-1500 $\mathrm{mL}$ of an infusion solution). After completing 11 courses of HAIC, serum creatinine increased to $1.8 \mathrm{mg} / \mathrm{dL}$, and eGFR decreased to $29.2 \mathrm{~mL} / \mathrm{min} / 1.73 \mathrm{~m}^{2}$. Thus, the dose of

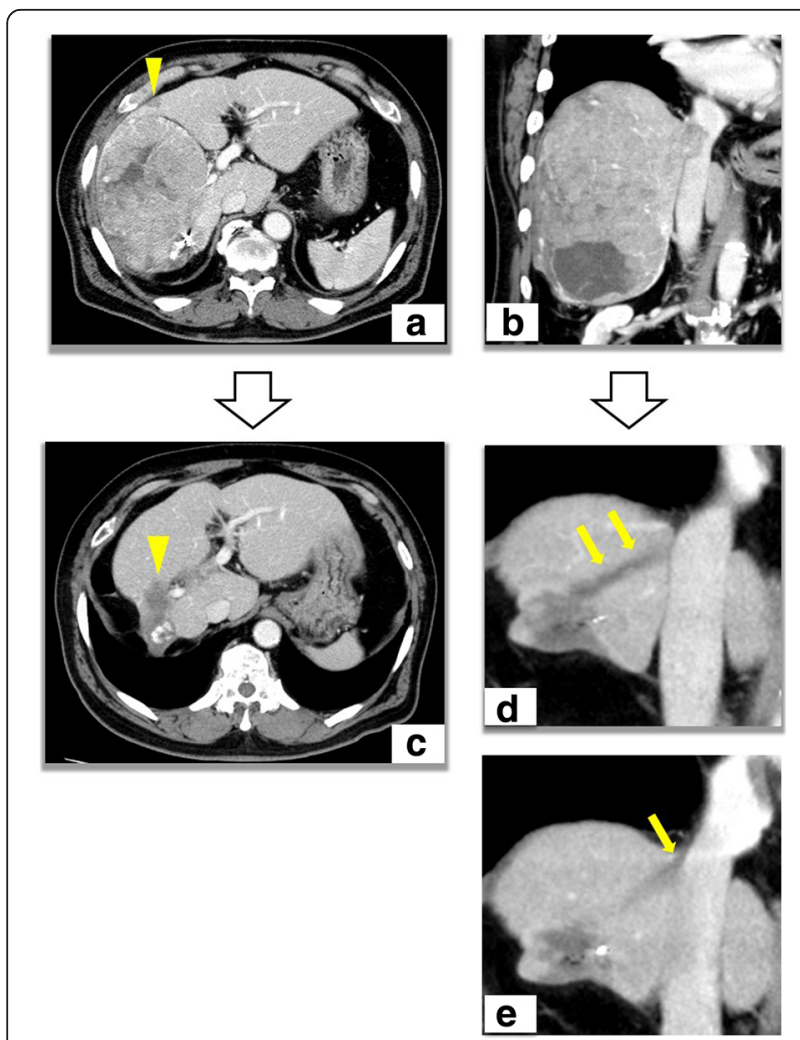

Fig. $1 \mathrm{CT}$ of the abdomen. a HCC with a maximum diameter of $16.0 \mathrm{~cm}$ in the right lobe detected before HAIC; intrahepatic metastasis is marked by the arrowhead. $\mathbf{b} \mathrm{HVTT}$ extending from the RHV to the IVC prior to HAIC. c The size of the main HCC markedly decreased (arrowhead), with no obvious intrahepatic metastases after 13 courses of HAIC. d-e After 13 courses of HAIC, the advanced part of the HVTT went down to the root of the RHV (arrows)
CDDP was decreased by $50 \%$ in the 12 th and 13 th courses of HAIC.

After 13 courses of HAIC, CT showed a marked decrease in the size of the main HCC, with no obvious intrahepatic metastases, thus indicating a partial response of the main HCC (Fig. 1c). Furthermore, the advanced part of the HVTT went down to the root of the RHV (Fig. 1d, e). Serum AFP and PIVKA-II levels decreased to $13 \mathrm{ng} / \mathrm{mL}$ and $15 \mathrm{mAU} / \mathrm{mL}$, respectively (Table 2). However, after two months from the last HAIC, serum creatinine increased to $1.93 \mathrm{mg} / \mathrm{dL}$, and eGFR decreased to $27.1 \mathrm{~mL} / \mathrm{min} / 1.73 \mathrm{~m}^{2}$. Because continuation of HAIC using CDDP became difficult due to progressive renal dysfunction, liver resection was selected as a radical treatment.

The results of liver function tests after 13 courses of HAIC were the following: ALT, 14 IU/L; AST, $19 \mathrm{IU} / \mathrm{L}$; serum albumin, $4.5 \mathrm{~g} / \mathrm{dL}$; PT/INR, 1.11; total serum bilirubin, $0.6 \mathrm{mg} / \mathrm{dL}$; and ICG-R15, $9.7 \%$ (Table 2). The Child-Pugh score was 5 . The volume of the whole liver was predicted to be $1082 \mathrm{~mL}$ by CT volumetry, and the volume of the estimated remnant liver (left lobe) was predicted to be $785 \mathrm{~mL}$, resulting in an estimated resection rate of $27.4 \%$. Because of the 13 courses of HAIC, we assumed that the HVTT rigidly adhered to the wall of the RHV from the peripheral side to the root of the $\mathrm{RHV}$, and a hepatectomy with patch graft venoplasty of the root of the RHV was planned. To avoid further progression of renal dysfunction, active veno-venous bypass was planned for preventing renal venous congestion and hypotension during IVC clamping.

After laparotomy via a thoracoabdominal incision, the right hepatic artery and the right portal vein were resected. Parenchymal transection for the right hepatectomy was performed by the anterior approach using the liver hanging maneuver. After the short hepatic veins were resected, the IVC was encircled at the suprahepatic IVC, the retrohepatic IVC just below the confluence of the common channel of the left and middle hepatic veins, and the retrohepatic IVC below the RHV. After cannulation of the axillary vein and the common iliac vein through the saphenous vein, veno-venous bypass using the Bio-Pump was activated. The IVC was clamped below the RHV with a DeBakey clamp and above the RHV with a straight vascular clamp, which was diagonally positioned to preserve the blood flow of the common channel of the left and middle hepatic veins. Since rigid adherence of the HVTT to the wall of the root of the RHV was suspected, the IVC wall located caudally to the root of the RHV was incised (Fig. 2a). The HVTT progressed to the cranial side and adhered to the IVC wall. Thus, the IVC wall at the cranial side of the root of the RHV was resected (Fig. 2b). The resultant surgical defect created in the wall of the IVC measured 
Table $\mathbf{2}$ Laboratory data after 13 courses of hepatic arterial infusion chemotherapy

\begin{tabular}{|c|c|c|c|c|c|}
\hline \multicolumn{4}{|c|}{ Complete blood count } & \multicolumn{2}{|l|}{ Tumor markers } \\
\hline WBC & $5,100 / \mu \mathrm{L}$ & ChE & $307 \mathrm{IU} / \mathrm{L}$ & AFP & $13 \mathrm{ng} / \mathrm{mL}$ \\
\hline $\mathrm{RBC}$ & $323 \times 10^{4} / \mu \mathrm{L}$ & LDH & $191 \mathrm{IU} / \mathrm{L}$ & PIVKA-II & $15 \mathrm{mAU} / \mathrm{mL}$ \\
\hline $\mathrm{Hb}$ & $10.3 \mathrm{~g} / \mathrm{dL}$ & T-Chol & $245 \mathrm{mg} / \mathrm{dL}$ & & \\
\hline $\mathrm{Hct}$ & $30.5 \%$ & TP & $7.0 \mathrm{~g} / \mathrm{dL}$ & Dye clearance test & \\
\hline \multirow[t]{2}{*}{ Plt } & $14.6 \times 10^{4} / \mu \mathrm{L}$ & Alb & $4.5 \mathrm{~g} / \mathrm{dL}$ & ICG-R 15 & $9.7 \%$ \\
\hline & & $\mathrm{Na}$ & $140 \mathrm{mEq} / \mathrm{L}$ & & \\
\hline \multicolumn{2}{|c|}{ Coagulation tests } & K & $5.4 \mathrm{mEq} / \mathrm{L}$ & $\mathrm{CT}$ volumetry & \\
\hline PT-INR & 1.11 & $\mathrm{Cl}$ & $106 \mathrm{mEq} / \mathrm{L}$ & Whole liver & $1082 \mathrm{ml}$ \\
\hline APTT & $28.0 \mathrm{sec}$ & $\mathrm{Ca}$ & $9.8 \mathrm{mg} / \mathrm{dL}$ & Right lobe & $297 \mathrm{ml}(27.4 \%)$ \\
\hline \multicolumn{2}{|c|}{ Blood chemistry } & UA & $8.6 \mathrm{mg} / \mathrm{dL}$ & Left lobe & $785 \mathrm{ml}(72.6 \%)$ \\
\hline AST & $19 \mathrm{IU} / \mathrm{L}$ & UN & $34.9 \mathrm{mg} / \mathrm{dL}$ & & \\
\hline ALT & $14 \mathrm{IU} / \mathrm{L}$ & $\mathrm{Cr}$ & $1.93 \mathrm{mg} / \mathrm{dL}$ & & \\
\hline ALP & $231 \mathrm{IU} / \mathrm{L}$ & CRP & $0.28 \mathrm{mg} / \mathrm{dL}$ & & \\
\hline$\gamma \mathrm{GTP}$ & $21 \mathrm{IU} / \mathrm{L}$ & $\mathrm{HbA1c}$ & $5.8 \%$ & & \\
\hline T.Bil & $0.6 \mathrm{mg} / \mathrm{dL}$ & eGFR & $27.1 \mathrm{~mL} / \mathrm{min} / 1.73 \mathrm{~m}^{2}$ & & \\
\hline
\end{tabular}

AFP alpha-fetoprotein, Alb albumin, ALT alanine aminotransferase, $A L P$ alkaline phosphatase, $A P T T$ activated partial thromboplastin time, $A S T$ aspartate aminotransferase, ChE cholinesterase, CRP C-reactive protein, eGFR estimated glomerular filtration rate, $\gamma G T P$ gamma glutamyl transpeptidase, $H B V$ hepatitis $B$ virus, $H b$ hemoglobin, $H b A 1 c$ hemoglobin A1c, Hct hematocrit, HCV hepatitis C virus, ICG-R 15 indocyanine green dye retention rate at 15 min, $L D H$ lactate dehydrogenase, Plt platelets, $P T$-INR prothrombin time-international normalized ratio, RBC red blood cells, T.Bil total bilirubin, T.Chol total cholesterol, PIVKA-II protein induced by vitamin $\mathrm{K}$ absence or antagonist, TP total protein, UA uric acid, UN urea nitrogen, WBC white blood cells

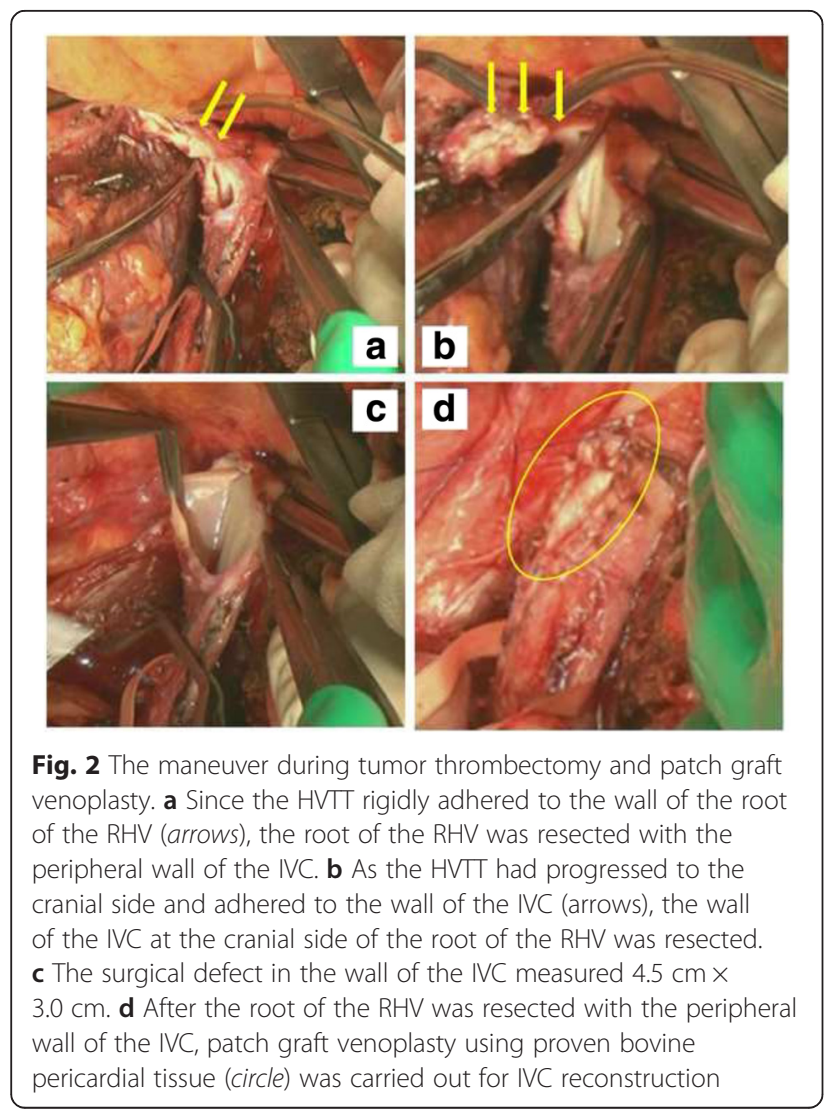

$4.5 \mathrm{~cm} \times 3.0 \mathrm{~cm}$ (Fig. 2c). Reconstruction of the IVC was performed by patch graft venoplasty using bovine pericardial tissue (Edwards Lifesciences Co., Ltd, Tokyo, Japan), resulting in good patency of the IVC (Fig. 2d). IVC clamp time was $31 \mathrm{~min}$, and the duration of active veno-venous bypass was $42 \mathrm{~min}$. During IVC clamping, systolic blood pressure was maintained at around 90-110 mmHg.

Macroscopic findings of the resected specimen showed the main HCC and the HVTT that rigidly adhered to the wall of the RHV from the peripheral side to the root of the RHV (Fig. 3). Histological examination revealed foci of a moderately differentiated $\mathrm{HCC}$ with extensive fibrosis and necrosis in the main HCC (Fig. 4a). Histologically, the HVTT in the RHV showed massive necrosis and tightly adhered to the vascular wall of the RHV (Fig. 4b, c). The patient had an uneventful postoperative course, with good remnant liver function. Serum creatinine and eGFR were $1.52 \mathrm{mg} / \mathrm{dL}$ and $35.1 \mathrm{~mL} / \mathrm{min} /$ $1.73 \mathrm{~m}^{2}$, respectively, indicating preservation of renal function. The patient did not show signs of recurrence 15 months after the surgery.

\section{Discussion}

Safety and efficacy of HAIC using powdered CDDP for advanced HCC have been demonstrated in several studies $[8,9]$. Since Yoshikawa et al. [9] reported that the overall response rate was $33.8 \%$ in 80 patients with advanced HCC without extrahepatic metastases, HAIC 


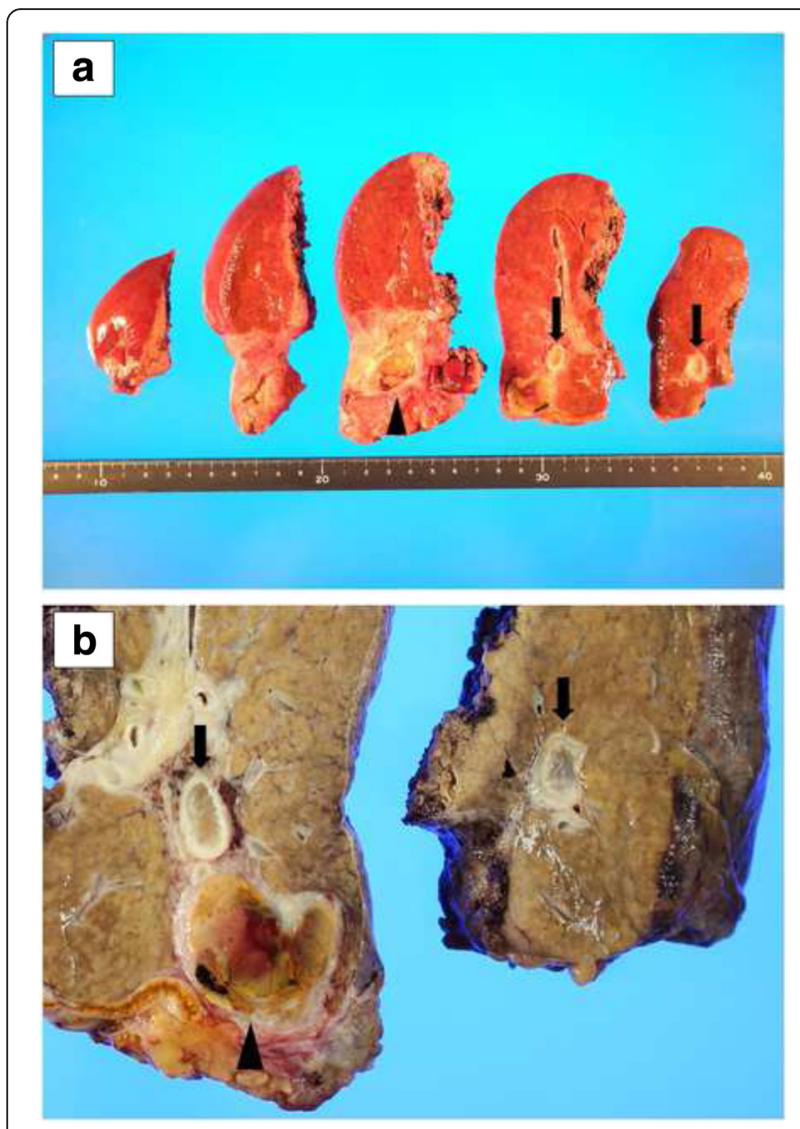

Fig. 3 Macroscopic findings of the resected specimen. a The resected specimen before fixation. $\mathbf{b}$ The resected specimen after fixation. Macroscopic findings of the resected specimen showed the main HCC (arrowhead) and the HVTT adhering rigidly to the wall of the RHV from the peripheral side to the root of the RHV (arrows)

with powdered CDDP was selected to treat the advanced HCC presented in this report. By using this treatment, the size of the main HCC markedly decreased, and intrahepatic metastases became undetectable. Furthermore, the advanced part of the HVTT went down from the IVC to the root of the RHV, leading to patient survival with good quality of life for over 17 months. However, due to the progression of renal dysfunction, HAIC using CDDP could not be continued. Renal dysfunction has been already reported as a side effect of HAIC using CDDP in another study [9].

The antitumor activity of CDDP is cell cycle nonspecific and mainly dependent on the concentration of non-protein-bound platinum (Pt) [10]. However, the blood concentration of non-protein-bound Pt markedly decreases after CDDP administration, and the half-life is less than $60 \mathrm{~min}$. [11] Since arterial infusion of CDDP can provide a higher concentration of $\mathrm{Pt}$ in the tumor compared with intravenous infusion [12], HAIC using powdered CDDP is an excellent therapy in accordance with CDDP pharmacokinetics. In contrast, side effects of
CDDP, including nephrotoxicity, are closely related to the blood concentration of non-protein-bound (Pt) [10]. Although CDDP-induced nephrotoxicity is transient and reversible in most cases, some of the patients with acute nephrotoxicity develop irreversible renal dysfunction [13]. In the present case, eGFR on admission was $43.7 \mathrm{~mL} / \mathrm{min} / 1.73 \mathrm{~m}^{2}$, indicating latent renal dysfunction due to diabetes mellitus and hypertension. It has been reported that nephrotoxicity increases with the dose and frequency of administration of CDDP and with the cumulative dose of CDDP $[14,15]$. In the present case, the cumulative dose of CDDP reached $780 \mathrm{mg} / \mathrm{m}^{2}$ and may have caused irreversible renal dysfunction.

Usually HVTT extending to the IVC can be simply removed by thrombectomy without IVC wall resection, because the HVTT does not adhere to the wall of both the main hepatic vein and the IVC [16-18]. However, in the present case, we assumed that the HVTT rigidly adhered to the wall of the RHV from the peripheral side to the root of the RHV due to the 13 courses of HAIC. The preoperative CT scan showed suspected adhesions between the HVTT and the wall of the RHV and IVC, later confirmed by the macroscopic findings of the resected specimen. Thus, the root of the RHV was resected with the peripheral wall of the IVC, creating a surgical defect in the wall of the IVC measuring $4.5 \mathrm{~cm} \times 3.0 \mathrm{~cm}$. Although side clamping of the IVC might have been possible in this case, we decided to carry out total IVC clamping to achieve safety and certainty of the reconstruction of the surgical defect in the wall of the IVC. As a result, good patency of the IVC was achieved by patch graft venoplasty using proven bovine pericardial tissue, leading to the prevention of chronic renal venous congestion caused by IVC stenosis.

IVC thrombectomy is usually carried out under bleeding control by hepatic vascular exclusion (HVE) with or without extracorporeal bypass [16-18]. In the present case, the IVC could be clamped above the RHV for preserving blood flow to the common channel of the left and middle hepatic veins. Thus, HVE was unnecessary, and blood flow of the remnant liver was maintained during patch graft venoplasty of the IVC, preserving remnant liver function.

When IVC thrombectomy is simple and short, extracorporeal bypass during HVE might be unnecessary. However, when the duration of HVE is long enough to trigger hemodynamic instability, extracorporeal bypass from the IVC and/or portal vein to the superior vena cava (SVC) should be performed [18]. In the present case, since the HVTT adhered to the wall of the RHV and the IVC, resection of the root of the RHV including the peripheral wall of the IVC and 

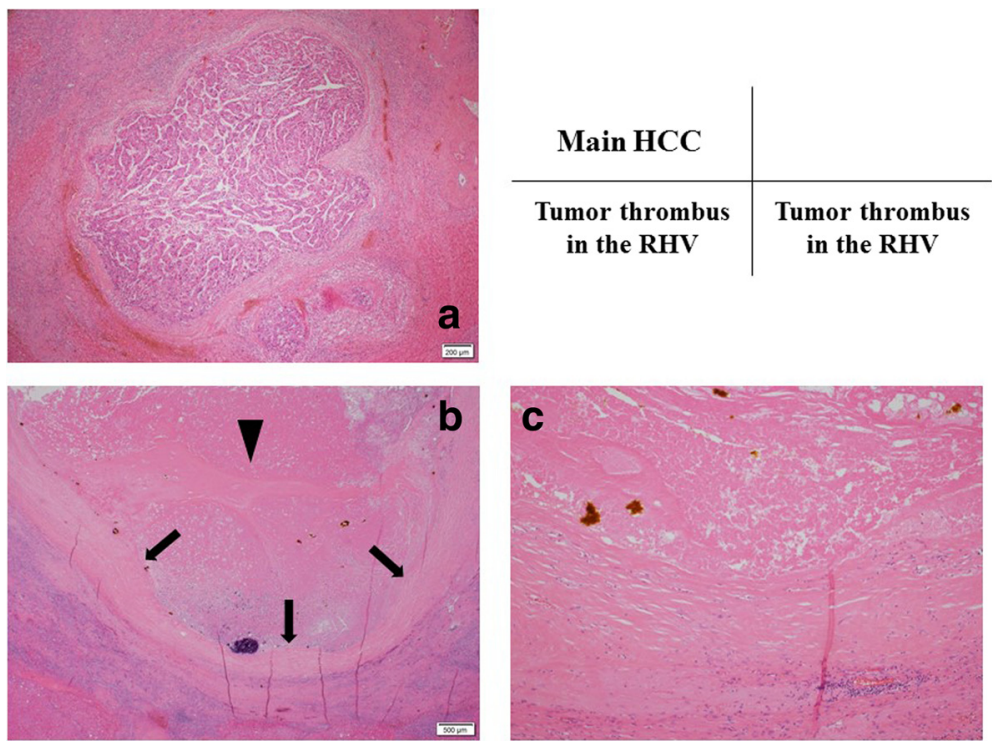

Fig. 4 Microscopic findings of the resected specimen. a Foci of a moderately differentiated HCC were observed with extensive fibrosis and necrosis in the main HCC. $\mathbf{b}$ The HVTT in the RHV presented massive necrosis (arrowhead) and tightly adhered to the vascular wall of the RHV (arrows) in a wide area. $\mathbf{c}$ In the high-power field showing tight adhesion between the HVIT and the wall of the RHV, the endothelial cells of the RHV disappeared

patch graft venoplasty of the IVC were necessary. Thus, the duration of IVC clamping was longer than that of a usual IVC thrombectomy, and progression of renal dysfunction caused by the surgical procedure had to be avoided.

Venous congestion, rather than impairment of cardiac output, is associated with the development of acute kidney injury in acute heart failure $[19,20]$. On the other hand, acute renal venous congestion has been closely related to acute renal failure in a clinical case of aortocaval fistula associated with ruptured aortic aneurysm and in an experimental model of aortocaval fistula that causes a rapid pronounced rise in central venous pressure [21-23]. Therefore, in the present case, veno-venous bypass from the IVC to the SVC using the Bio-Pump was activated to prevent renal venous congestion and hemodynamic instability during total IVC clamping. As a result, hemodynamic stability was maintained during IVC clamping, and postoperative renal function was preserved.

\section{Conclusions}

Prognosis of HCC patients with HVTT extending to the IVC is poor [3, 4]. Surgical resection alone can provide long-term survival only in some HCC patients with HVTT $[5,6,17]$. Clinical trials of hepatic resection combined with chemotherapy, including HAIC, have been reported to improve the survival rate of $\mathrm{HCC}$ patients with macrovascular invasion [24-26].
In the present case, HAIC using CDDP in combination with hepatic resection and patch graft venoplasty of the IVC provided a good long-term outcome with no HCC recurrence. Furthermore, deterioration of renal dysfunction was avoided by using active veno-venous bypass during IVC clamping to prevent renal venous congestion and hypotension.

\section{Authors' contributions}

$\mathrm{Al}, \mathrm{HS}, \mathrm{KM}$, and $\mathrm{KY}$ conceived the idea for this case report and wrote the manuscript. MT, TU, and KS performed the analysis on the antitumor effect of HAIC, and TH performed the radiological analysis. KO performed the histological analysis. $\mathrm{MH}, \mathrm{SO}$, and NT critically helped with data interpretation. All authors edited the manuscript for important intellectual content and approved the final version.

\section{Competing interests}

The authors declare that they have no competing interests

\section{Consent for publication}

Written informed consent was obtained from the patient for publication of this case report and of the related images. A copy of the written consent is available for review by the Editor-in-Chief of this journal.

\section{Ethics approval and consent to participate}

This case report was not required to be reviewed by the Institutional Review Board committee at the Fukuyama City Hospital. This case report was carried out in compliance with the Helsinki Declaration.

\section{Author details}

'Department of Gastroenterological Surgery, Fukuyama City Hospital, 5-23-1 Zao, Fukuyama 721-8511, Japan. ${ }^{2}$ Department of Internal Medicine, Fukuyama City Hospital, Fukuyama, Japan. ${ }^{3}$ Department of Radiology, Fukuyama City Hospital, Fukuyama, Japan. ${ }^{4}$ Department of Pathology, Fukuyama City Hospital, Fukuyama, Japan. 
Received: 17 August 2015 Accepted: 25 August 2016

\section{Published online: 01 September 2016}

\section{References}

1. Ikai I, Yamaoka Y, Yamamoto Y, Ozaki N, Sakai Y, Satoh S, et al. Surgical intervention for patients with stage IV-A hepatocellular carcinoma without lymph node metastasis. Ann Surg. 1998;227:433-9.

2. Poon RT, Fan ST, Ng IO, Wong J. Prognosis after hepatic resection for stage IVA hepatocellular carcinoma: a need for reclassification. Ann Surg. 2003;237: $376-83$

3. Le Terut YP, Hardwigen J, Ananian P, Saisse J, Gregoire E, Richa H, et al. Resection of hepatocellular carcinoma with tumor thrombus in the major vasculature: a European case-control series. J Gastrointest Surg. 2006;10:855-62.

4. Pawlik TM, Poon RT, Abdalla EK, Ikai I, Narorney DM, Belghiti J, et al. Hepatectomy for hepatocellular carcinoma with major portal tumour-cell invasion and migration: diversity and escape or hepatic vein invasion: results of a multicenter study. Surgery. 2005;137:403-10.

5. Kokudo T, Hasegawa K, Yamamoto S, Shindoh J, Takemura N, Aoki T, et al. Surgical treatment of hepatocellular carcinoma associated with hepatic vein tumor thrombosis. J Hepatol. 2014:61:583-8.

6. Wang Y, Yuan L, Ge Rl, Sun Y, Wei G, et al. Surgical benefit of surgical treatment for hepatocellular carcinoma with inferior vena cava/right atrium tumor thrombus: Results of a retrospective cohort study. Ann Surg Oncol. 2013;20:914-22

7. Murakami E, Aikata H, Miyaki D, Nagaoki Y, Katamura Y, Kawaoka T, et al. Hepatic arterial infusion chemotherapy using 5 -fluorouracil and systemic interferon-afor advanced hepatocellular carcinoma in combination with or without three-dimensional conformal radiotherapy to venous tumor thrombosis in hepatic vein or inferior vena cava. Hepatol Res. 2012;42: $442-53$.

8. Osaki A, Suda T, Kamimura K, Tsuchiya A, Tamura Y, Takamura M, et al. A safe and effective dose of cisplatin in hepatic arterial infusion chemotherapy for hepatocellular. Cancer Medicine. 2013;2:86-98.

9. Yoshikawa M, Ono N, Yodono H, Ichida T, Nakamura H. Phase II study of hepatic arterial infusion of a fine-powder formulation hepatic arterial infusion chemotherapy of cisplatin for advanced hepatocellular carcinoma. Hepatol Res. 2008:38:474-83.

10. Belt RJ, Himmelstein KJ, Patton TF, Bannister SJ, Sternson LA, Repta AJ. Pharmacokinetics of non-protein-bound species following administration of cis-dichlorodiammineplatinum (II). Cancer Treat Rep. 1979;63:1515-21.

11. Kawashiro T, Asakawa N. Pharmacokinetics of fine powder cisplatin (DDP-H) for intraarterial infusion chemotherapy. Antibiot Chemother. 2004;20:103-8. Japanese.

12. Collins JM. Pharmacokinetic rationale for intra-arterial therapy. In: Kimura K, editor. Cancer Chemotherapy, Challenges for the Future, vol. 4. Amsterdam: Excerpta Medica; 1989. p. 3-10.

13. Kidera Y, Kawakami H, Sakiyama T, Okamoto K, Tanaka K, Takeda M, et al. Risk factors for cisplatin-induced nephrotoxicity and potential of magnesium supplementation for renal protection. PLoS One. 2014;9(7): e101902.

14. Miller RP, Tadagavadi RK, Ramesh G, Reeves WB. Mechanisms of cisplatin nephrotoxicity. Toxins. 2010;2:2490-518.

15. Madias NE, Harrington JT. Platinum nephrotoxicity. Am J Med. 1978;65:307-14.

16. Nonami T, Nakao A, Harada A, Kaneko T, Kurokawa T, Takagi H. Hepatic resection for hepatocellular carcinoma with a tumor thrombus extending to inferior vena cava. Hepatogastroenterology. 1997:44:798-802.

17. Liu J, Wang Y, Zhang D, Liu B, Ou Q. Comparison of survival and quality of life of hepatectomy and thrombectomy using total hepatic vascular exclusion and chemotherapy alone in patients with hepatocellular carcinoma and tumor thrombi in the inferior vena cava and hepatic vein. Eur J Gastroenterol Hepatol. 2012;24:186-94.

18. Wakayama K, Kamiyama T, Yokoo H, Kakisaka T, Kamachi H, Tsuruga Y, et al. Surgical management of hepatocellular carcinoma with tumor thrombi in the inferior vena cava or right atrium. World J Surg Oncol. 2013;11:259-68.

19. Mullens W, Abrahams Z, Francis GS, Sokos G, Taylor DO, Starling RC, et al. Importance of venous congestion for worsening of renal function in advanced decompensated heart failure. J Am Coll Cardiol. 2009:53:589-96.

20. Wattad M, Darawsha W, Solomonica A, Hijazi M, Kaplan M, Makhoul BF, et al. Interaction between worsening renal function and persistent congestion in acute decompensated heart failure. Am J Cardiol. 2015;115:932-7.
21. Albalate M, Octavio JG, Llobregat R, Fuster JM. Acute renal failure due to aortocaval fistula. Nephrol Dial Transplant. 1998;13:1268-70.

22. Weber T, Gewertz B, Stanley I, Lindenauer S, Fry W. Renal effects of acute infrarenal aortocaval fistula. J Surg Res. 1978:25:482-7.

23. Burke AM, Jamieson GG. Aortocaval fistula associated with ruptured aortic aneurysm. Br J Surg. 1983;70:431-3.

24. Fukuda S, Okuda K, Imamura M, Imamura I, Eriguchi N, Aoyagi S. Surgical resection combined with chemotherapy for advanced hepatocellular carcinoma with tumor thrombus: report of 19 cases. Surgery. 2002;131: $300-10$.

25. Nagano H, Miyamoto A, Wada H, Ota H, Marubashi S, Takeda Y, et al. Interferon-alpha and 5-fluorouracil combination therapy after palliative hepatic resection in patients with advanced hepatocellular carcinoma, portal venous tumor thrombus in the major trunk, and multiple nodules. Cancer. 2007:110:2493-501.

26. Katagiri S, Yamamoto M. Multidisciplinary treatments for hepatocellular carcinoma with major portal vein tumor thrombus. Surg Today. 2014;44: $219-26$.

\section{Submit your next manuscript to BioMed Central and we will help you at every step:}

- We accept pre-submission inquiries

- Our selector tool helps you to find the most relevant journal

- We provide round the clock customer support

- Convenient online submission

- Thorough peer review

- Inclusion in PubMed and all major indexing services

- Maximum visibility for your research

Submit your manuscript at www.biomedcentral.com/submit
) Biomed Central 